\title{
The pain experiences of powered wheelchair users
}

\author{
Andrew O. Frank FRCP *', Lorraine H. De Souza PhD ${ }^{2}$, Julia L. Frank BSc ${ }^{2}$, \\ Claudius Neophytou MSc ${ }^{2}$.
}

\author{
' Stanmore Specialist Wheelchair Service + \\ Royal National Orthopaedic Hospital, Brockley Hill, Stanmore, HA7 4LP, UK \\ ${ }^{2}$ Centre for Research in Rehabilitation, School of Health Science and Social Care \\ Mary Seacole Building, Brunel University, Uxbridge, Middlesex, UB8 3PH \\ * Author for correspondence: \\ Email: andrew.frank I@btinternet.com \\ Tel: $+44(0) 1923285362$ \\ + Stanmore Specialist Wheelchair Service has now been disbanded. Address for \\ correspondence is Centre for Research in Rehabilitation, School of Health Sciences and Social \\ Care, Mary Seacole Building, Brunel University, Uxbridge, Middlesex, UB8 3PH \\ Tel: $+44(0)$ I895 268847
}

Keywords: Assistive technology; pain; users' experiences; wheelchair users; powered wheelchairs 


\begin{abstract}
Purpose: To explore the experience of pain and discomfort in users of electric powered indoor/outdoor wheelchairs (EPIOCs) provided by a National Health Service.
\end{abstract}

Methods: EPIOC users receiving their chair between February and November 2002 (N=74) were invited to participate in a telephone questionnaire/interview and 64 (aged 10-81) agreed. Both specific and open-ended questions examined: presence of pain/discomfort, its severity, minimising and aggravating factors, particularly in relation to the EPIOC and its use.

Results: Most EPIOC users described experiences of pain with 17\% reporting severe pain. Over half felt their pain was influenced by the wheelchair and few (25\%) considered their chair eased their symptoms. The commonest strategy for pain relief was taking medication. Other self help strategies included changing position, exercise and complementary therapies. Respondents emphasised the provision of backrests, armrests, footrests and cushions which might alleviate or exacerbate pain, highlighting the importance of appropriate assessment for this high dependency group.

Conclusions: Users related pain to their underlying medical condition, their wheelchair, or a combination of the two. User feedback is essential to ensure the EPIOC meets health needs with minimum of pain. This becomes more important as the health condition of users changes over time. 


\section{Implications for Rehabilitation}

- Pain is frequently experienced by users of powered wheelchairs and may be severe

- Clinicians need to distinguish between wheelchair-related pain and pain due to an underlying health condition

- Improved design and additional features to powered wheelchairs should reduce this pain and suffering but at a financial cost 


\section{Introduction}

Pain and discomfort are commonly experienced by wheelchair users [1-2]. Much of the literature relates to musculo-skeletal pain experienced by self propelling wheelchair users who experience arm pain, often in the shoulder [3-5], wrist [6] or neck [7]. Indeed the presence of wheelchair users' shoulder pain is an indication for powered wheelchair use [8].

The concept of 'powered mobility' is very broad and the literature often embraces scooters under this terminology [9-10]. Powered wheelchairs may themselves be computerised or the base for robotic aids to independence [11]. Provision of powered mobility in the UK through the United Kingdom National Health Service (NHS) has however been strictly limited to those fulfilling eligibility criteria [12]. Since 1996 Electric Powered Indoor/outdoor Wheelchairs (EPIOCs) have been provided by the NHS. They are bigger than electric powered indoor chairs (EPICs) which were the only powered wheelchairs provided by the NHS prior to 1996. EPICs are designed to be used around the home, are compact and have a maximum speed of 2 miles (3.2 kilometres) per hour. By contrast, electric powered outdoor wheelchairs (EPOCs) are designed for use on many terrains (including roads) with a maximum speed of 6 miles $(9.7 \mathrm{~km})$ per hour and remain seldom provided by the NHS. EPIOCs fit in between these two chairs with a maximum speed of 4 miles $(6.4 \mathrm{~km})$ per hour and therefore are a compromise, being designed to be used from bedroom to shops via pavements. Recently the boundaries have become blurred with many EPIOCs developing features previously only seen on EPOCs. Thus some EPIOCs now have a suspension to help provide a smoother ride and powered tilt-in-space and recline features are now more readily affordable and on many models.

Pain or discomfort are experienced by $26 \%$ of EPIOC users early after EPIOC provision [13], but this rose to $46 \%$ when a similar population of EPIOC users were reviewed 2 years after 
provision [14]. For some, this pain might be severe and may increase during the day [15]. These studies have not differentiated between pain arising from the underlying impairment [16-19] or pain relating to the wheelchair and its use.

EPIOC users sit in their chair up to $15.5 \mathrm{~h}$ per day [15], on average about $10 \mathrm{~h}$ [14]. As most have impaired ability to move inside their chair (because they are a severely disabled population dictated by the eligibility criteria [13]), some discomfort would be expected. However, many will require specialised seating in order to counteract their postural instability [20]. Indeed, many users need postural support over the $24 \mathrm{~h}$ period and a large number of systems are available to "optimize the disabled person's ability to function" [20]. The authoritative review of specialised seating [20] does not include any discussion on the value of specialised seating on pain relief. However, it has been demonstrated that adult users of powered chairs rate comfort as the most important objective for their adaptive seating [21] and providing comfort in addition to providing support was highly rated by parents of children using wheelchairs [22]. The need for changing support over time has been reported in users with muscular dystrophy for whom pain was a major issue [23].

The primary purpose of EPIOC provision is to seek the best compromise between facilitating mobility, postural support and environmental utility. It is the complexity of the (often) multiple impairments [24] and the interaction with the user's environment and lifestyle that dictates these compromises. Some of these compromises may result in users' experience of pain and discomfort being aggravated by the prolonged period of sitting which these chairs are designed to facilitate. Little is known about how powered wheelchair users cope with this pain and discomfort. While it is known from clinical records that some have been prescribed analgesics, what is not known is how medication or other strategies are used to alleviate pain. 
Some strategies may involve professional advice whilst others may be initiated by wheelchair users themselves. Thus, much might be learned from users by exploring the strategies they use to diminish their pain and discomfort - an area which appears not to have been investigated in a powered wheelchair user population.

The aim of this study was to explore the 'lived' experience of pain in a cohort of powered wheelchair users about one year after provision of the wheelchair, and the strategies used to minimise the pain and discomfort.

\section{Methods}

This study used a qualitative research approach to elicit a range of views from EPIOC users. In addition, the study also utilised diagnostic and quantitative data to complement and enhance the qualitative findings [25].

\section{The setting}

The Specialist Wheelchair Service at Stanmore was set up in 1997 in response to the new NHS provision of Electric Powered Indoor/outdoor Wheelchairs (EPIOCs) [12]. It provided a regional service for a population of around 3.1 million people from both rural and inner city areas. Further details have been reported previously [26], as have the eligibility criteria for the provision of an EPIOC [13]. These criteria were subsequently applied to all referrals irrespective of age. However, age-related appropriate levels of independence were required of children.

\section{Participants and recruitment}

All EPIOC users $(\mathrm{N}=74)$ identified on the Stanmore Specialist Wheelchair Service departmental database who received their chair between February and November 2002 were invited to participate. Following provision of information about the study 64 consented verbally 
to participate. Parental consent was obtained for those under 16 years of age. Harrow Research Ethics Committee approved the study for both children and adults.

\section{Interview methodology}

A qualitative approach was used to investigate the perceptions and experiences of the respondents and to understand their interpretations of their experience of pain and discomfort when using an EPIOC.

There are several qualitative research methods available [27] and the most appropriate for this research study was the 'FrameWork' approach [28-30]. This approach allows for in depth interviews to be carried out using a topic guide where the topics form points of focus for a conversation between the interviewer and respondent. The Framework approach is appropriate for identifying themes related to perceptions and for understanding the views underlying people's experiences. It has been used previously with EPIOC users [26,31-32] and back pain patients [33-37]. The approach allows for consistency in the interview method and also flexibility in the flow of the discussion [38]. The topics guiding the conversation are those related to the research questions, in this case experience of pain and discomfort and the strategies used to minimise them.

This research formed part of a wider programme of research focussed on the 'lived' experiences of EPIOC users living in the community [13,23,26,31-32,39-41]. The aspect of the research reported here sought to explore the impact of wheelchair users' pain and discomfort on their everyday lives and the strategies they used to alleviate their pain.

\section{Procedure}


Appointments were made and interviews were carried out by telephone in order to reduce logistical barriers to research participation [42]. Because of the severity of their impairment, 18 users needed assistance to complete the interviews. This consisted of help from a reading assistant for those using communication aids and screen writing, or assistance with interpretation for users with speech or hearing impairments. This is similar to the communication methods used by participants in previous research with people with similarly profound impairments [43]. Assistance was also provided in cases where the user was unable to hold a telephone without help and the questions and responses were relayed by the assistant. The forms of assistance provided were mainly to allow for audible comprehension and as a method to relay the users' views directly to the interviewer. We decided to use this method in order to allow all users equal opportunity as research participants to voice their views and perceptions, rather than setting up restrictions in the methods that could exclude the full participation of those with profound communication impairments. For the 18 users needing help, those providing the help were parents, spouses or formal carers. The assisted responses are identified by an asterix in the text. Forty-six users completed interviews without any assistance and interviews were carried out 1019 (mean 14.3) months after chair delivery.

A researcher independent of the NHS wheelchair service carried out the interviews. This was clarified to participants along with the steps to be taken to allow for total anonymity and confidentiality. A priori interview topics were determined based on items from the EuroQol EQ5D, such as pain/discomfort, and independence [44]. This has been used previously with adult EPIOC users [40]. The topic guide also included issues raised during a pre-study interview with user group representatives to reflect the full spectrum of user's experiences and views. Care was taken in the wording of interview questions to take an open stepped approach in the ordering and 
structuring of questions. Initial questions were open-ended and general allowing the initial questioning to be topic led and subsequently all nuances of users' (including children's) views and opinions to be elicited and expressed. The same process was used for all interviews.

The topic guide addressed the following issues:-

1. In general, which statement best applies to you [44]:

a. I have no pain or discomfort

b. I have moderate pain or discomfort

c. I have extreme pain or discomfort

2. Do you do anything to minimise the pain?

Would you mind telling me a little bit more about what you do to minimise the pain?

3. Is your pain or discomfort affected when using your EPIOC?

How?

Is your pain or discomfort specifically affected by any of the following items:

i. Kerb climbers

ii. $\quad$ Seating

iii. Back rest

iv. Loads

If so, how?

4. Is there anything else you wish to add concerning pain or discomfort and the use of your EPIOC?

These questions were a subset of the topics used in a wider interview of users' experiences of their EPIOCs. Each interview lasted approximately 30 minutes (range 20-67) and was audio-tape recorded and transcribed verbatim. All transcripts and tapes were anonymised. 
Medical records were reviewed to document diagnosis, date of birth, gender and information about previous chair use.

\section{Methods of analysis}

The accuracy of the interview data was checked by comparison of each transcript text with the original audio recording. Thematic analysis was applied using the process described by Ritchie et al [28] for the analysis of contextual qualitative data. This method tends to be more structured than those analytical methods used in other qualitative research as it is more explicit and more strongly informed by a priori reasoning [45]. Themes related to the topics of research interest were extracted from the data and organised into charts and tables. The analysis then focussed on refining the evolving themes and identifying the range and pattern of the users' perspectives. An interpretative analysis was carried out to provide explanations for the findings.

Demographic and diagnostic data were analysed using Excel 2003, to determine proportions and percentages of the study population for descriptive purposes.

\section{Results}

\section{Participants}

Sixty-four EPIOC users participated in the study. The users consisted of 32 men with a mean age of 46 (range 12-75, SD 18.5) years and 32 women with a mean age of 38 (range 10-81, SD 23.5) years. Their diagnoses were predominantly neurological and are shown in Table 1 [26]. Users had been in receipt of their EPIOC for a mean of 14 (range 9 - 19) months. 
Table 1 - User diagnosis by age and sex, reproduced with permission from [26]

\begin{tabular}{|l|c|c|c|c|}
\hline Diagnosis & Female & Male & Total & Age (mean, range, sd) \\
\hline $\begin{array}{l}\text { Muscular } \\
\text { dystrophy }\end{array}$ & 1 & 11 & 12 & $18.5(10-54$, sd 12.) \\
\hline Cerebral Palsy & 6 & 4 & 10 & $25(12-46$, sd 13) \\
\hline $\begin{array}{l}\text { Multiple } \\
\text { Sclerosis }\end{array}$ & 5 & 3 & 8 & $53(32-71$, sd 15) \\
\hline $\begin{array}{l}\text { Spinal Cord } \\
\text { Injury }\end{array}$ & 2 & 4 & 6 & $61.5(34-77$, sd 19.) \\
\hline $\begin{array}{l}\text { Cerebrovascular } \\
\text { Disease }\end{array}$ & 3 & 2 & 5 & $59(40-81$, sd 16) \\
\hline $\begin{array}{l}\text { Rheumatoid } \\
\text { Arthritis }\end{array}$ & 4 & 1 & 5 & $54.2(40-64$, sd 9.) \\
\hline $\begin{array}{l}\text { Other } \\
\text { Neurological }\end{array}$ & 2 & 2 & 4 & $44.3(33-61$, sd 12) \\
\hline Spina Bifida & 2 & 2 & 4 & $31.3(14-53$, sd 18.) \\
\hline $\begin{array}{l}\text { Other musculo- } \\
\text { skeletal }\end{array}$ & 3 & 0 & 3 & $50.3(38-57$, sd 11 \\
\hline $\begin{array}{l}\text { Multiple } \\
\text { impairments }\end{array}$ & 2 & 1 & 3 & $66.3(50-75$, sd 14) \\
\hline Polio & 1 & 1 & 2 & $60.5(57-64$, sd 5) \\
\hline Other & 1 & 1 & 2 & $30.5(16-45$, sd 21) \\
\hline Total & $\mathbf{3 2}$ & $\mathbf{3 2}$ & $\mathbf{6 4}$ & $\mathbf{4 1 . 7 ( 1 0 - 8 1 , ~ s d ~ 2 1 . 4 ) ~}$ \\
\hline
\end{tabular}

\section{Interviews}

Forty six interviews were completed by users alone, whilst eighteen were completed by a user and a carer as co-respondents. Twelve of these were a parent with a child EPIOC user (11 mothers and one father), three were partner/spouses, two were children with a parent chair user and one was a lay carer of a disabled individual. Results reporting findings where a carer was a co-respondent are identified with an asterix. Age-related groups from this cohort have been described previously [31-32].

Emergent themes 
The themes that emerged from the interview data were pain in relation to sitting, the critical nature of the support structures of the chair, posture and seating, pain and discomfort when out and about in the EPIOC and pain relating to the underlying medical condition.

\section{The experience of pain}

In response to the questions posed, $55(86 \%)$ users reported experiencing pain or having strategies for pain relief relating to sitting in past or present wheelchairs. Forty-three $(67 \%)$ experienced pain using their current EPIOC. Eleven (17\%) described their pain as severe, five (8\%) described their pain as moderate to severe, 27 (42\%) experienced moderate pain and 21 (33\%) reported experiencing no pain. There was an indication that the severity of pain increased with age with those without pain being, on average, 34y (range 11-77, SD 22); those with moderate pain being 40y (range 10-76, SD 22); those with pain between moderate to extreme being 65y (range 41-81, SD 15) and those with extreme pain being 50y (range 29-71, SD 12). Only one user without pain $(\mathrm{n}=21)$ had a musculoskeletal diagnosis whilst three with severe pain $(n=11)$ had such a diagnosis. Those reporting no pain had 12 users with congenital impairments or a muscular dystrophy compared to only two with severe pain.

Analysis of the 'in-depth' interviews indicated that 38 (59\%) users described ways in which they felt their pain was influenced by their EPIOC and $19(30 \%)$ reported pain or discomfort aggravated by sitting. An important emerging theme focussed on pain in relation to the duration of sitting:

"When sitting for long periods, the pain gets progressively worse" [user 4, cerebral palsy, aged 12].

For some users, the problem was attributed to the seating system: 
"Gets discomfort if sits in it for more than 2 hours ... I don't think it can be helped. With anyone, if you're sitting in the same position, you just get up, don't you, but he can't, so we just move him" [User 54*, Acquired neurological disorder, aged 61].

Other users reported pain relief following adjustments to the EPIOC:

"The back. Gets backache. This is because of his posture, leaning forward. Has had a special back rest made. [Did that help?] Yes and no. He thinks that it can be improved upon" [User 27*, cerebral palsy, aged 18].

Several users described the critical nature of the support structures within the EPIOC:

"I have a .....back support which helps. It does because it's higher than the last one I had and it supports my shoulders a bit more" [User 66, cerebrovascular disease, aged 47].

"I've got a contoured back and a jelly seat, they do help a little bit" [User 19, lower limb amputee, aged 50].

However, there were some reports of difficulties in obtaining a resolution with wheelchair adaptations:

“That's why I'm getting a new one. They're changing the seating for me" [User 57, cerebral palsy, aged 18].

In some cases, particularly for younger EPIOC users, these difficulties were attributed to poor posture: 
"Her posture is very bad. She almost sits at between 45 and 60 degrees. So she's uncomfortable and she's got aches and pains ... Because of her posture, she's not sitting that well. In her lower back she's got more pain because she's sitting so far forward . . they ordered a different kind of tray for more support for her arms" [User 48*, muscular dystrophy, aged 14].

Despite the difficulties, $16(25 \%)$ users commented on reduced pain and discomfort with EPIOC use. These users appeared very satisfied with both their EPIOC and the service provided:

"With this new chair, I have no pain . This latest chair is really great because it's padded and it's very comfortable...I don't get bruised, sore and my back doesn't hurt so much...I can sit up better. Of course I'm deteriorating all the time. I just wish I had this chair years and years ago. I could have done an awful lot more". [User 30, Multiple Sclerosis, aged 69].

Several users described how seemingly trivial changes in wheelchair adaptations affected their pain experience:

“The foot rests do need careful positioning if everything's going to be reasonably comfortable. It has been adjusted" [User 73, cerebrovascular disease, aged 81].

Seventeen $(27 \%)$ commented on the use of cushions, padding and gel seats, many commenting on the difficulty in finding the right cushion for them: 
"For a long, long while I was very uncomfortable because they couldn't get the right cushion for me. They tried every cushion going. But now they've found one" [User 39, acquired neurological condition, aged 39].

For others, finding the most comfortable solution for their wheelchair comfort involved more complex cushion adaptations:

"I've got a cushion because I'm bony. Gets sore after a while sitting on it. . . I've got a tendency to lean on my left side, the weak side. I lean on the elbow, so I've had the arm rest cushioned to help with this" [User 26, multiple sclerosis, aged 42].

For a small number of users, obtaining the correct cushion was vital in the prevention of pressure sores.

"I've got one of those ... I call them cushions with the tea bag in because that's what they look like. They build me up, one side. It does help and it stops you getting sores as well" [User 53, Multiple sclerosis, aged 63]

The final emergent theme was that of pain and discomfort caused by users being out and about in the EPIOCs and dealing with environmental hazards:

"It jolts me around. It makes it worse. Environment outside, it's a bit uncomfortable suspension wise. Because I've got the osteoarthritis" [User 33, multiple sclerosis aged 44].

The jolting associated with kerbs and pavement potholes was not helped by the earlier designs of EPIOCs: 
“There's no suspension on them. It's just a solid frame . . . 'boomp' and you're down" [User 19, lower limb amputee, aged 50].

One user gave a graphic account of his experience:

"Sometimes I get more pain when I'm going up kerbs. Especially if I jolt or if there's a bumpy pavement and there's a lot of those and I just get a jolting through my back because there's no suspension on a wheelchair so it just travels straight up my back" [User 17, cerebrovascular disease, aged 64].

\section{Pain relating to the underlying medical condition}

Fifteen users made miscellaneous comments relating to their pain, of which five users specifically commented that the pain related to their underlying illness rather than wheelchair related issues, although one of the five was not certain, and two users also specifically commented on aggravation of their pain in cold or damp weather:

"It actually gives me more freedom because my disease itself, rheumatoid arthritis, that stops me doing everything near enough. I don't even like being parted from it in hospital” [User 70, rheumatoid arthritis, aged 54].

"The weather is another factor. If it's cold, I have more pain" [User 33, Multiple Sclerosis, aged 44]).

\section{Strategies for pain relief}

In response to queries $45(70 \%)$ users reported a strategy for pain relief. The strategies used comprised two main categories:- firstly strategies that involved the wheelchair user carrying out actions of their own volition that ameliorated their pain and discomfort and secondly strategies 
related to the need for adjustments to the wheelchair or its constituent parts which were the responsibility of the wheelchair service.

The most frequently used self-help strategy was use of analgesia which was reported by $30(47 \%)$ users. Most of the users taking analgesics did not specify the nature of the analgesics, although four were taking codeine preparations and one user took Tramadol. Some users reported taking muscle relaxants and antispasticity medication. A minority took two or three different preparations.

Other self-help strategies included changing position in their chair [user 54], getting out of the chair [user 3] and doing exercise and/or physiotherapy which were each reported by 8 (13\%). Some typical quotes were:

“Takes a paracetamol. Does stretching exercises at school [User 25*, muscular dystrophy, aged 14].

"I have to keep on the move, changing positions and that sort of thing. Not that the chair is uncomfortable, it's just me. I like to keep moving all the time" [User 53, multiple sclerosis, aged 63].

"I just have to manoeuvre my legs a little bit. I even experience the discomfort in bed. So it's constant anyway, it makes no difference" [User 34, cerebral palsy, aged 46].

Other self-help strategies included massage, herbal medicines, taking a bath, sitting down and keeping occupied. A small number used complementary therapies to help their pain: 
"I have lymphatic drainage massage every day. I have a whole bath and I have all these herbal medicines." [User 9, cerebrovascular disease, aged 40].

Other comments related to the suitability of the wheelchair and its component parts to the comfort of the user. Appropriate adjustments to the assistive technology were reported as alleviating the pain and discomfort in addition to the alleviation of other problems e.g. pressure sores.

Use of recline and/or tilt was reported by $3(5 \%)$, and adjusting footrests/armrests and pressure relief were each reported by $2(3 \%)$ :

"It has a tilt back which makes it easier to get into and more comfortable." [User 30, multiple sclerosis, aged 69].

Four users reported medical strategies for pain relief such as use of transcutaneous electrical nerve stimulation, rubbing cream into a foot, having a transfusion and attending a pain clinic. Three did not report having pain but made comments about its relief and one user reported pain but had no strategy for pain relief.

\section{Discussion}

Two thirds of EPIOC users in this cohort described themselves as being in pain or discomfort when sat in their wheelchair, of which nearly two thirds of those in pain used analgesia, confirming that pain is a major issue for EPIOC users. The pain was described as severe for a minority (17\%) of users. According to the respondents, the provision of backrests, armrests, 
footrests and cushions might alleviate or exacerbate the pain and this emphasises the importance of appropriate assessment for equipment provision. Service providers need to utilise the users' self assessments of comfort in making this provision. Appropriate support for weakened body structures is likely to be equally important for those with or without a painful underlying condition. Many users will also have musculoskeletal comorbidities in addition to their primary diagnosis. Thus a report of 544 EPIOC users showed that the third most frequent diagnosis (inclusive of comorbidities) was spinal pain, noted in $13 \%$ of the cohort [46].

Our findings report the pain experiences of EPIOC users after they have been using their wheelchairs for over a year. Providers need to be aware that pain due to provision of the EPIOC is more likely to arise some months after supply of the wheelchair. The current lack of follow-up arrangements prevalent in some wheelchair services is likely to result in peoples' pain being inadequately addressed.

The development of new services for the provision of powered chairs in the UK has had a clear focus on mobility issues rather than addressing wider issues relating to participation in the community [24]. Thus wheelchairs with a riser function are seldom available through the NHS. This function raises the body of the user to a similar height to non-disabled colleagues, family or friends to facilitate: communication and reduce awkwardness, access to cupboards at home or at work and access to books in libraries etc. However experience in delivering services to this severely dependent group of users has indicated a need to look at their health and quality of life in a more holistic manner [40] and over a period of time.

\section{Aggravation of pain}

Our users appear to describe a progression in their symptoms which might begin with a little stiffness but end up with a need to change position (which for many is impossible without 
assistance) or to take medication. It has been shown that for some users pain increases dramatically in relation to the time spent sitting in their EPIOC [15]. In this study one of the main findings was of consistent reports from EPIOC users of pain due to prolonged sitting in their chair. However it is possible that this is an unavoidable consequence of the strategy to provide a fully supported chair with minimum requirement for painful and costly (to users, family or paid carers) transfers. This was certainly a view of a number of users.

The findings in this research demonstrate that the provision of technology can affect the levels of pain and discomfort, either positively or negatively. These EPIOC users were very clear when reporting discomfort relating to small details of the wheelchair e.g. the position of back, arm or foot supports. The findings reported here provide some insight into the expertise acquired by the EPIOC users into managing their own conditions on a day to day basis. Their knowledge and experience is essential in order to ensure that the equipment provided is actually meeting their precise needs. Therefore, user feedback should be actively sought in all assessments. It is recognised, however, that the final best fit chair for the user will often be a compromise after consideration of environmental and personal circumstances.

The importance of the relationship between poor posture and increased discomfort was mostly reported by parents and teenage users. It is likely that this reflects growth of young people whose growth spurt may be faster than a service can respond to. This has been previously reported for young EPIOC users with muscular dystrophy [23]. In conditions like cerebral palsy, this might also reflect increased spasticity along with growth in the teenage years.

The findings in this study also draw attention to the fact that correctly applied seating and adjustments to the EPIOC are important for pain relief. Indeed, in the user's mind, the association of pain consequent to inadequate support in the wheelchair is so obvious that it is 
often not stated. The British Society of Rehabilitation Medicine's National Clinical Guidelines on Specialised Wheelchair Seating did not specifically identify significant pain as a major issue, although they called for further evidence on wheelchair users' comfort [20]. They noted the relationship of comfort to prolonged sitting, as well as the need for careful reassessment during years of rapid growth. This is clearly a matter of concern to young EPIOC users and their parents and further research into this issue is needed.

Until recently EPIOCs lacked important features of electric powered outdoor chairs e.g. suspension. This data supports the view that the lack of suspension is a considerable factor in aggravating wheelchair users' pain through jolting relating to travelling over uneven surfaces, kerbs and so forth. The association between vibration caused by going over uneven surfaces/pavements has been investigated in able-bodied people using wheelchairs for research purposes [47-48]. It is widely accepted that pain, particularly back pain is common in car drivers exposed to whole body vibration including shocks and jolts [49]. In the light of both the available evidence and the reports from these wheelchair users, further research in wheelchair users would be warranted. Although these environmental hazards appeared not to prevent most of the EPIOC users in this study from going outside it may well limit the likelihood of going out, particularly for older users [32].

It is not clear why pain was experienced more in the older users. Whilst one would expect musculoskeletal problems to be painful, they represented a small proportion of this sample. However, many of these users had neurological conditions that would be associated with painful spasticity or neurogenic pain. This sample of users had a wide variety of conditions, none of which dominated the group reporting extreme pain. It is not clear from our findings whether or not the pain is primarily due to suboptimal EPIOC support, changes in the underlying medical 
condition or inappropriate pain medication. It is likely that a combination of factors is present for many. This emphasises the importance of a multiprofessional approach to meeting the seating needs of these profoundly dependent users.

\section{Alleviation of pain}

Two major themes emerged. One focussed on the needs and actions of the individual, whilst the other related to their interaction with their EPIOC. The majority of users reported their own individual strategies for pain relief, although many took medication as part of those strategies, there is also strong evidence of a range of self-care strategies. Some of these may have been carried out as a result of advice from health professionals (e.g. exercises) but some are clearly strategies drawn from alternative medicine (e.g. herbal remedies). The users also reported strategies that they had often initiated regarding adjustments to their chairs, which were primarily the responsibility of the service provider.

The importance of cushions, and having the right type, was a significant finding. This is not surprising because pain induced by prolonged pressure might be minimised by use of appropriate pressure relieving cushions [50], and might inhibit some of the worst effects of jarring and jolting. It was disappointing to note the problems some chair users had in acquiring a comfortable cushion. In our experience, many service providers have an inadequate stock of cushions to facilitate a trial period of sitting and have not developed a pattern of service provision that allows users to sit on a trial cushion for a reasonable period of time. Other commonly used strategies reported by our users included wriggling inside, and getting out of, the chair for those able to do so. However, only some individuals had enough independent movement to use this as a strategy. Some parents physically moved their children to help 
alleviate pain but for this group of EPIOC users there will be some who cannot move for themselves or be easily moved by another person.

Powered tilt and recline are established methods of increasing comfort [21,51-52]. It has been found that powered wheelchair users utilised their powered tilt-in-space and/or recline functions at least hourly, spending more than one third of their time in tilted and reclined positions [51]. At the time of this study (2002) EPIOCs with tilt were not readily available and only a few users would have been offered a recline feature. Our current experience is that the combination of tilt and recline features can make an enormous difference to the experience of pain because users have a large number of postural options with these facilities [21], in addition to the numerous other advantages of such systems, as described by the Rehabilitation Engineering \& Assistive Technology of North America (RESNA) [52]. Advances in assistive technology are likely to continue to provide resolution of pain and discomfort, at least for some EPIOC users. However, the increased cost of providing assistive technology may result in it being available for fewer users.

\section{Limitations of the study}

Interviewing by telephone is not the ideal technique for those with severe physical impairments, particularly when communication difficulties are present. This complicates distinguishing comments made with the assistance of others more difficult as no non-verbal communication can take place. Similarly, it is harder to be sure that young EPIOC users' have their views correctly interpreted by their parents. However, we have no reason to doubt that the responses did not genuinely represent the views of the EPIOC users as their views reflected clinical experience with these individuals. 
Diagnostic data is given to the wheelchair service by the user and not via a professional referral. However, our experience when discussing individual users with their general practitioners is that users have given appropriate diagnostic information. Future studies would be improved if accurate records are obtained about analgesic consumption and data on pain experience were quantified by one of the many scales available.

This study took place at a time when wheelchairs with tilt-in-space features were only just being introduced into NHS provision. It is clear that this feature is now more widely provided (Frank and De Souza unpublished data) and we would expect that would have a major impact on the levels of pain experienced. Likewise the increasing provision of chairs with suspension is likely to reduce the painful effects of jolting and jarring during outdoor use.

\section{Points for service commissioners}

EPIOCs do not just provide a social function to increase participation - important though that is. They also improve comfort and well-being and have clinical therapeutic implications. Appropriately prescribed chairs may reduce analgesic consumption and the risks that follow from analgesic use (e.g. constipation resulting from opioid consumption in a group already predisposed to this problem).

There are cost implications to providing the most appropriate chair - particularly in the provision of tilt-in-space features which may often be linked to provision of a recline function to reduce painful hip flexion or back pain without users sliding down in their chairs with the additional risk of skin breakdown. Likewise there are cost implications to providing adequate follow-up visits. Commissioners would be advised to commission research into the most 
appropriate form of follow-up to detect adverse health outcome following provision of a chair e.g. pain or pressure sores.

The financial implications of the capital cost of providing the most suitable wheelchair can sometimes be minimised by appropriate use of the voucher scheme with charitable partners or the Department for Work and Pensions when the user is working [53].

\section{Points for clinicians}

In the United Kingdom, the importance of wheelchair and specialist seating provision is embedded in The National Service Framework for Long Term (Neurological) Conditions [54]. Clinicians need to understand the importance of appropriate wheelchair features to give adequate support for weakened limbs, spine and trunk. These needs change over time because the condition of the user might change (deteriorating condition, adolescence, gain in weight and so forth). Consequently, users of Specialised Wheelchair Seating provision require regular review which is frequently lacking $[13,23,32]$. In addition, and in the light of these results, the views and experiences of the EPIOC users should form part of the formal review.

Individual EPIOC users have complex disabilities, often relating to multiple impairments. Some of their diagnoses will have pain as a known symptom. Therefore, it cannot be assumed that all reports of pain are due to wheelchair and seating problems. Rehabilitation professionals need to have a clear understanding of both the underlying condition and the impact of the chair on the pain. Successful management will require careful balancing between assessment and treatment of the underlying health condition and the prescription of assistive technologies. The chair user should have full participation in their management which clinicians should ensure by 
inviting views to be expressed. Pain experiences reported by the chair user while not using the chair (e.g. when lying in bed) would suggest that the underlying problem needs addressing. However, this problem itself might be aggravated by inappropriate wheelchair and seating provision.

\section{Conclusion}

The EPIOC users described many experiences of pain related both to their powered chair and seating and to their underlying condition. They had developed a variety of strategies for alleviating the pain or coping with it.

Their reliance on specialist help and support to gain the correct assistive technologies was essential for reducing their pain and improving their comfort. However, current provision remains imperfect and improvements will best be achieved by rehabilitation professionals working in partnership with wheelchair users to achieve appropriate pain management over time.

\section{Acknowledgements}

We gratefully acknowledge the advice and assistance of Elizabeth and Peter Kemp from the National Forum of Wheelchair User Groups for initial identification of themes of relevance to wheelchair users; and to Mrs Jennifer Taylor for secretarial assistance.

Declarations of interest: The authors have none to declare. This work was partly funded by the North West Thames Regional Audit Fund. 


\section{Reference List}

[1] Crane BA, Holm MB, Hobson D, Cooper RA, Reed MP, Stadelmeier S. Test-retest reliability, internal item consistency, and concurrent validity of the wheelchair seating discomfort assessment tool. Assistive Technology 2005; 17(2):98-107.

[2] Crane BA, Holm MB, Hobson D, Cooper RA, Reed MP, Stadelmeier S. Development of a consumerdriven Wheelchair Seating Discomfort Assessment Tool (WcS-DAT). [Report]. International Journal of Rehabilitation Research March 2004; 27(1):85-90.

[3] Collinger JL, Boninger ML, Koontz AM, Price R, Sisto SA, Tolerico ML et al. Shoulder biomechanics during the push phase of wheelchair propulsion: a multisite study of persons with paraplegia. Archives of Physical Medicine \& Rehabilitation 2008; 89(4):667-676.

[4] Mercer JL, Boninger M, Koontz A, Ren D, Dyson-Hudson T, Cooper R. Shoulder joint kinetics and pathology in manual wheelchair users. Clinical Biomechanics 2006; 21(8):781-789.

[5] Curtis KA, Roach KE, Applegate EB, Amar T, Benbow CS, Genecco TD et al. Reliability and validity of the Wheelchair User's Shoulder Pain Index (WUSPI). Paraplegia 1995; 33:595-601.

[6] Wei SH, Huang S, Jiang CJ, Chiu JC. Wrist kinematic characterization of wheelchair propulsion in various seating positions: implication to wrist pain. Clinical Biomechanics 2003; 18(6):S46-S52.

[7] Boninger ML, Cooper RA, Fitzgerald SG, Lin J, Cooper R, Dicianno B et al. Investigating neck pain in wheelchair users. American Journal of Physical Medicine \& Rehabilitation 2003; 82(3):197-202.

[8] Nash MS, Koppens D, van HM, Sherman AL, Lippiatt JP, Lewis JE. Power-assisted wheels ease energy costs and perceptual responses to wheelchair propulsion in persons with shoulder pain and spinal cord injury. Archives of Physical Medicine \& Rehabilitation 2008; 89(11):2080-2085.

[9] Auger C, Demers L, Gelinas I, Jutai J, Fuhrer MJ, DeRuyter F. Powered mobility for middle-aged and older adults: systematic review of outcomes and appraisal of published evidence. American Journal of Physical Medicine \& Rehabilitation 2008; 87(8):666-680.

[10] Brandt A, Kreiner S, Iwarsson S. Mobility-related participation and user satisfaction: construct validity in the context of powered wheelchair use. Disability \& Rehabilitation Assistive Technology 2010; 5(5):305-313.

[11] Brose SW, Weber DJ, Salatin BA, Grindle GG, Wang H, Vazquez JJ et al. The role of assistive robotics in the lives of persons with disability. American Journal of Physical Medicine \& Rehabilitation 2010; 89(6):509-521.

[12] Department of Health. Powered indoor/outdoor wheelchairs for severely disabled people. NHS executive Health Service Guidelines HSG(96)34[May 1996]. London: Dept. of Health, 1996.

[13] Frank AO, Ward JH, Orwell NJ, McCullagh C, Belcher M. Introduction of the new NHS Electric Powered Indoor/outdoor Chair (EPIOC) service: benefits, risks and implications for prescribers. Clin Rehabil 2000; 14(December):665-673.

[14] Frank AO, McCullagh C, Pugh M, Orwell NJ, Blackman G, Belcher M. Attempted systematic annual review of a regional EPIOC service. 2001.

[15] Gibson J, Frank A. Pain experienced by electric-powered chair users: a pilot exploration using pain drawings. Physiotherapy research international : the journal for researchers and clinicians in physical therapy 2005; 10(2):110-115. 
[16] Castle K, Imms C, Howie L. Being in pain: a phenomenological study of young people with cerebral palsy. Developmental Medicine \& Child Neurology 2007; 49(6):445-450.

[17] Jock MT. Pain management in patients with multiple sclerosis. Pain Research and Management 2000; 5(1):77-80.

[18] Douvillez B, Braillon P, Hodgkinson I, Berard C. Pain, osteopenia and body composition of 22 patients with Duchenne muscular dystrophy: A descriptive study. Annales de Readaptation et de Medecine Physique 2005; 48(8):616-622.

[19] Shariff F, Carter J, Dow C, Polley M, Salinas M, Ridge D. Mind and body management strategies for chronic pain and rheumatoid arthritis. Qualitative Health Research 2009; 19(8):1037-1049.

[20] British Society of Rehabilitation Medicine. Specialised wheelchair seating national clinical guidelines. Report of a multidisciplinary expert group (Chair: Marks, LJ). 1-39. 2004. London, British Society of Rehabilitation Medicine.

[21] Lacoste M, Weiss L, Allard M, Dansereau J. Powered tilt/recline systems: why and how are they used? Assistive Technology 2003; 15(1):58-68.

[22] Telfer S, Solomonidis S, Spence W. An investigation of teaching staff members' and parents' views on the current state of adaptive seating technology and provision. Disability and Rehabilitation: Assistive Technology 2010; 5(1):14-24.

[23] Richardson M, Frank AO. Electric powered wheelchairs for those with muscular dystrophy: problems of posture, pain and deformity. Disability and Rehabilitation Assistive Technology 2009; 4(3):181-188.

[24] World Health Organization: report by the secretariat. The International Classification of functioning, disability and health (ICIDH-2). Geneva: World Health Organisation, 2001.

[25] Sandelowski M. Real qualitative researchers do not count: the use of numbers in qualitative research. Research in Nursing \& Health 2001; 24(3):230-240.

[26] Frank AO, Neophytou C, Frank J, De Souza LH. Electric Powered Indoor/outdoor Wheelchairs (EPIOCs): users views of influence on family, friends and carers. Disability \& Rehabilitation Assistive Technology 2010; 5(5):327-338.

[27] Ritchie J, Lewis J. Qualitative Research Practice: A Guide for Social Science Students and Researchers. First ed. London. Thousand Oaks. New Delhi: Sage Publications; 2003.

[28] Ritchie J, Spencer L, O'Connor W. Carrying out qualitative analysis. In: Ritchie J, Lewis J, editors. Qualitative Research Practice: a guide for social science students and researchers. First ed. London: Sage Publications; 2003. 219-262.

[29] Quinton S, Mitchell M. Chronically Sick and Disabled Persons Act 1970: presented pursuant to c44 1970 Section 22. London: Department of Health, 2002

[30] National Centre for Social Research. FrameWork: The qualitative data analysis tool. 2010. London, National Centre for Social Research. http://www.framework-natcen.co.uk/

[31] Evans S, Neophytou C, De Souza LH, Frank AO. Young people's experiences using electric powered indoor-outdoor wheelchairs (EPIOCs): potential for enhancing users' development? Disabil Rehabil 2007; 19(16):1281-1294. 
[32] Evans S, Frank A, Neophytou C, De Souza LH. Older adults' use of, and satisfaction with, electric powered indoor /outdoor wheelchairs. Age and ageing 2007; 36(4):431-435.

[33] Hush JM, Refshauge K, Sullivan G, De SL, Maher CG, McAuley JH. Recovery: what does this mean to patients with low back pain? Arthritis \& Rheumatism 2009; 61(1):124-131.

[34] Hush JM, Refshauge KM, Sullivan G, De SL, McAuley JH. Do numerical rating scales and the Roland-Morris Disability Questionnaire capture changes that are meaningful to patients with persistent back pain? Clinical rehabilitation 2010; 24(7):648-657.

[35] De Souza LH, Frank AO. Subjective pain experience of people with chronic back pain. Physiotherapy Res Int 2000; 5(4):207-219.

[36] De Souza LH, Frank AO. Experiences of living with chronic back pain: the physical disabilities. Disabil Rehabil 2007; 29(7):587-596.

[37] De Souza LH, Frank AO. Patients' experiences of the impact of chronic back pain on family life and work. Disabil Rehabil 2011; 33(4):310-318.

[38] Arthur S, Nazroo J. Designing Fieldwork Strategies and Materials. In: Ritchie J, Lewis J, editors. Qualitative Research Practice: A Guide for Social Science Students and Researchers. 1 ed. London. Thousand Oaks. New Delhi: Sage Publications; 2003. 109-137.

[39] Belcher M, Frank AO. Survey of the use of transport by recipients of a Regional Electric Indoor/Outdoor Powered (EPIOC) wheelchair service. Disabil Rehabil 2004; 26(10):563-575.

[40] Davies A, De Souza LH, Frank AO. Changes in the quality of life in severely disabled people following provision of powered indoor/outdoor chairs. Disability and Rehabilitation 2003; 25(6):286290.

[41] Serif T, Ghinea G, Frank AO. Visualizing Pain Data for Wheelchair Users: A Ubiquitous Approach. Journal of Mobile Multimedia (JMM) 2005; 1(2):161-177.

[42] Frazier LM, Miller VA, Horbelt DV, Delmore JE, Miller BE, Paschal AM. Comparison of focus groups on cancer and employment conducted face to face or by telephone. Qualitative Health Research 2010; 20(5):617-627.

[43] Lutz BJ, Bowers BJ. Disability in everyday life. Qualitative Health Research 2005; 15(8):1037-1054.

[44] The EuroQol Group. EuroQol EQ-5D user guide. [Version A]. The Netherlands, The EuroQol Foundation, 1996.

[45] Pope C, Ziebland S, Mays N. Qualitative research in health care: analysing qualitative data. BMJ 2000; 320(8 January):114-116.

[46] Frank AO. Who uses Electric Powered Indoor/outdoor wheelchairs (EPIOCS) in the UK National Health Service? retrospective review of 544 users. Exeter: Posture \& Mobility Group; 2010. 165-168.

[47] Cooper RA, Wolf E, Fitzgerald SG, Kellerher A, Ammer W, Boninger ML et al. Evaluation of selected sidewalk pavement surfaces for vibration experienced by users of manual and powered wheelchairs. Journal of Spinal Cord Medicine 2004; 27(5):468-475.

[48] Wolf E. Evaluation of electric powered wheelchairs and exposure to whole-body vibration. Dissertation Abstracts International: Section B: The Sciences and Engineering 2007; 68(3-B):1771. 
[49] Health \& Safety Laboratory. Whole body vibration and ergonomics of driving occupations: Ports industry. RR767. 2010. Derbyshire, Health \& Safety Executive.

[50] Krouskop TA, Cullen B, Garber SL. Custom selection of support surfaces for wheelchairs and beds: one size does not fit all. Dermatology Nursing 1992; 4(3):191-194.

[51] Ding D, Leister E, Cooper RA, Cooper R, Kelleher A, Fitzgerald SG et al. Usage of tilt-in-space, recline, and elevation seating functions in natural environment of wheelchair users. Journal of Rehabilitation Research \& Development 2008; 45(7):973-984.

[52] Dicianno BE, Arva J, Lieberman JM, Schmeler MR, Souza A, Phillips K et al. RESNA Position on the application of tilt, recline and elevating leg rests for wheelchairs. Assistive Technology 2009; 21:13-29.

[53] Frank AO, Ellis K, Yates M. Use of the voucher scheme for provision of Electric Powered Indoor/outdoor Wheelchairs (EPIOCs). Posture \& Mobility 2008; 23(1):17-26.

[54] Department of Health. The National Service Framework for Long-term Conditions. London: Department of Health; 2005. 